\title{
Effectiveness, tolerability and drop-out rates of Vortioxetine in comorbid depression: a naturalistic study
}

Running head. Vortioxetine: effectiveness, tolerability drop-out rate

\author{
Vera De Carlo ${ }^{1 *}$, Matteo Vismara ${ }^{1}$, Benedetta Grancini ${ }^{1}$, Beatrice Benatti ${ }^{1}$, Monica Francesca \\ Bosi $^{1}$, Anna Colombo', Caterina Adele Viganò ${ }^{1}$, Bernardo Dell'Osso ${ }^{1,2,3}$
}
${ }^{1}$ Department of Biomedical and Clinical Sciences "Luigi Sacco", University of Milan, Psychiatriy Clinic, Ospedale Sacco- Polo Universitario- ASST Fatebenefratelli-Sacco, Psychiatry, Milan, Italy.
${ }^{2}$ Stanford University, Department of Psychiatry and Behavioral Sciences, Stanford, CA 94305-5717, USA.
3"Aldo Ravelli" Center for Neurotechnology and Brain Therapeutic, University of Milan, 20142, Milan, Italy.

\section{*Corresponding Author: Vera De Carlo}

-Department of Biomedical and Clinical Sciences "Luigi Sacco", University of Milan, Psychiatriy clinic, Ospedale Sacco- Polo Universitario- ASST Fatebenefratelli-Sacco, Psychiatry, Milan, Italy. Via Giovanni Battista Grassi, 74, 20157 Milano (Ml), Italy.

-E-mail address: vera.decarlo@unimi.it, matteo.vismara@unimi.it

-Telephone number: +39 0239042803

-Fax:+39 0238201320

Key words: vortioxetine, affective disorders, effectiveness, tolerability, dropout.

Text language: English
Abstract: 200 words
Manuscript: 2763 words
References: 50
Tables: 3
Figures: 2




\section{ABSTRACT}

Objective. Vortioxetine is a novel antidepressant whose safety, tolerability and therapeutic action have been supported by several studies. The present naturalistic study aimed to characterize its effectiveness, tolerability and dropout rate in the real world. Methods. Total sample consisted of 66 outpatients with major depressive episode, treated with vortioxetine, whose clinical variables were evaluated over three time points. Results. Most common primary diagnoses were Major Depressive Disorder (45.5\%) and Bipolar Disorder (33.4\%), with an overall comorbidity rate of $48.5 \%$ and concomitant medications in the $89.4 \%$. The mean vortioxetine daily dosage was $12.90 \pm 5.65 \mathrm{mg}$. Effectiveness of vortioxetine through a significant improvement on specific psychometric scales emerged, while only a non significant trend of association between higher dosage and effectiveness was found. In the total sample the $51.5 \%$ was classified as responder, the $36.4 \%$ as remitter. Two thirds of subjects did not report side effects, while, in the reminder patients, gastrointestinal ones were the most frequent $(72.7 \%)$. Almost two thirds of the sample could complete the follow up, while the $36.4 \%$ dropped out; the main reasons of dropout were side effects $(37.5 \%)$ and lack of efficacy (29.2\%). Conclusions.Larger sample studies are warranted to better characterize vortioxetine effectiveness and tolerability in the real world. 


\section{INTRODUCTION}

Major depressive disorder (MDD) is a prevalent, burdensome and frequently comorbid psychiatric condition (Charara et al., 2017), associated with reduced quality of life and impaired cognitive functioning (Corruble \& Guelfi, n.d.; Papakostas, 2014).

Despite several compounds being approved for the treatment of MDD, roughly half of affected patients report an inadequate response to first-line antidepressant treatment (Papakostas, Nielsen, Dragheim, \& Tonnoir, 2018). Moreover, even though antidepressants represent the cornerstone in the treatment of MDD, available therapies often show several side effects (Rizvi \& Kennedy, 2011). Consequently, many depressed patients fail to remit after an initial antidepressant trial, often deciding to stop treatment and requiring an additional treatment switch (Rush et al., 2006). With respect to bipolar depression, this represents the most pervasive and difficult to treat phase of bipolar disorder (Galimberti et al., 2019) and, even though the utility of antidepressants in bipolar depression is still debated, they are largely used as augmentative agents for the treatment of bipolar depression (Dell'Osso et al., 2020). Ultimately, depressive episodes often occur in other psychiatric disorders (i.e. personality disorders or eating disorders, or obsessive compulsive disorder) as comorbidity and could complicate the course of primary illness (De Carlo, Calati, \& Serretti, 2016; Lochner et al., 2014; Zheng et al., 2019).

New generations of antidepressants aim at optimizing treatment efficacy and tolerability. Vortioxetine is, for instance, a novel antidepressant with multimodal activity (Papakostas et al., 2018), approved for the treatment of MDD in the last decade in many Countries worldwide (EMA (European Medicines Agency), n.d.; FDA, 2013). Its mechanism of action combines the inhibition of the serotonin transporter and the direct modulation of serotonin $(5-\mathrm{HT})$ receptor activity, being it a 5-HT1A receptor agonist, a 5-HT1B receptor partial agonist, a 5-HT3, a 5HT7, and a 5-HT1D receptor antagonist and an inhibitor of the 5-HT transporter (BangAndersen et al., 2011). Vortioxetine' safety, tolerability and therapeutic action over affective symptoms have been addressed by several studies (Berhan \& Barker, 2014; Jacobsen, Harper, Chrones, Chan, \& Mahableshwarkar, 2015), conducted with low (up to $10 \mathrm{mg} / \mathrm{day}$ ) 
(Alam, Jacobsen, Chen, Serenko, \& Mahableshwarkar, 2014; Baldwin, Hansen, \& Florea, 2012) and higher dosages (15-20 mg/day) (Jacobsen, Mahableshwarkar, Serenko, Chan, \& Trivedi, 2015). Moreover, this compound was found to be effective in the treatment of cognitive dysfunction of depression (Pehrson et al., 2015), in light of its pro-cognitive effects (Salagre, Grande, Solé, Sanchez-Moreno, \& Vieta, n.d.). Furthermore, vortioxetine' side effects differ from those of other antidepressants, according to the low incidence of sexual dysfunction and weight gain (Salagre et al., n.d.). Conversely, reports of gastrointestinal side effects, particularly nausea, seem to be highly associated with vortioxetine, mainly at the beginning of the treatment (Hughes, Lacasse, Fuller, \& Spaulding-Givens, 2017).

In the available literature, there is a limited amount of real world studies evaluating potential differences in terms of effectiveness, tolerability and dropout rate between patients treated with low vs higher daily doses of vortioxetine.

Therefore, the present naturalistic study aimed to characterize effectiveness and tolerability of vortioxetine in the real world, focusing on discontinuation rates and related reasons, in a sample of patients with other psychiatric and medical comorbidities, receiving mono and polytherapies and different dosages of vortioxetine.

Given that investigation of the aforementioned variables in the real world is substantially limited, we did not formulate any a priori hypothesis, in terms of effectiveness, tolerability and dropout rates in the total sample and across differential low vs higher dosage groups, also considering that vortioxetine was frequently administered in patients with poly-comorbidity, poly-therapy, long duration of illness and previous exposure to other antidepressants. 


\section{MATERIAL AND METHODS}

\subsection{Sample selection}

For the present observational study, 66 patients attending the psychiatric outpatient service of the Department of Mental Health of the Ospedale Luigi Sacco in Milan (Italy), were recruited. After receiving a full explanation of the protocol, all patients gave their informed consent for participating to the study.

Data were gathered directly from patients, assessed by psychiatrists or residents in psychiatry with specific training in mood disorders management, through a semi-structured interview based on the Diagnostic and Statistical Manual of Mental Disorders, 5th Ed. (DSM-5) (APA American Psychiatric, 2013), in order to ascertain psychiatric diagnoses and comorbidities, or through a retrospective review of patients' medical records from October 2015 to February 2019. In some cases, the interview took place with the presence of patients' relatives or caregivers, with their consent.

Eligible patients were adults (over age 18 years), with an ongoing Major Depressive Episode (MDE), according to the DSM-5 criteria (APA American Psychiatric, 2013) at the moment of the first vortioxetine prescription. The MDE could be related to a primary diagnosis of MDD or represent a comorbid condition. Indeed, patients could have a primary diagnosis of affective disorders (i.e., MDD-, Bipolar Disorder 1 or 2 -BD 1 or 2-), Anxiety Disorders (Generalized Anxiety Disorder -GAD-, Panic Disorder -PD-), Obsessive Compulsive Disorder -OCD-, Personality Disorders -PerD-, or another primary diagnosis (Adjustment Disorders -AD-, Eating Disorders -ED-). Exclusion criteria included: age $<18$ years old, the presence of brain diseases, mental retardation and psychiatric disorders secondary to a medical condition. Patients with different dosages of vortioxetine in the range of $5-20 \mathrm{mg} /$ day and different regimens in terms of unique versus multiple daily administration were included. Sociodemographic and clinical variables included: gender, age, age at onset, duration of illness, duration of untreated illness (DUI, defined as the time interval, in months, elapsing between the onset of the disorder and the administration of the first pharmacological treatment, in compliant patients, at an appropriate dosage and for an adequate period of time, in agreement 
with recently updated International Treatment Guidelines) (Bauer et al., 2013; Grunze et al., 2013), primary psychiatric diagnosis, psychiatric and medical comorbidities, psychiatric family history, prevalence and lifetime number of hospitalization, dosage and side effects of vortioxetine, and associated poly-therapy.

\subsection{Assessment}

Over three subsequent evaluations, the first one of which taking place when vortioxetine was started (T0), then after four weeks (T1) and after 3 months (T2), the following psychometric scales were administered: Hamilton Depression Rating Scale - 21 items (HAMD-21) (HAMILTON, 1967), Montgomery-Asberg Depression Rating Scale (MADRS) (Montgomery \& Asberg, 1979), Hamilton Anxiety Rating Scale (HAM-A) (HAMILTON, 1959), Young Mania Rating Scale (YMRS) (Young, Biggs, Ziegler, \& Meyer, 1978), Clinical Global ImpressionEfficacy Index (CGI) (W., 1976), Dosage Record Treatment Emergent Symptom Scale (DOTES) (Guy W, 1976) and Treatment Emergent Symptoms Write-In Scale (TWIS). We considered as response $\geq 50 \%$ decrease of HAM-D total score at $\mathrm{T} 1$ or $\mathrm{T} 2$, while as remission HAMD $\leq 7$ total score (De Carlo et al., 2016) at the end of follow up. Dropouts at T2 were not taken into account for statistical analysis related to remission rates, while dropouts at $\mathrm{T} 1$ were excluded for analysis on response rate.

\subsection{Statistical analysis}

Descriptive analyses of the total sample and comparative ones (i.e. vortioxetine low vs higher daily dosages, dropout vs not, combined antidepressant vs not) were performed, using $x 2$ tests for categorical variables and t test for continuous ones. Moreover, the response and remission rates in the total sample and across different groups of dosage were investigated. A two-tailed significance threshold was set at $p<0.05$. Furthermore, repeated measures ANOVA for psychometric scales were carried out on the total sample and across different groups of dosage (vortioxetine $\leq 10 \mathrm{mg} v s>10 \mathrm{mg}<15 \mathrm{mg}$ vs $\geq 15 \mathrm{mg}, 20 \mathrm{mg}$ vs other dosages, $20 \mathrm{mg}$ vs $\leq 10 \mathrm{mg}$ ). In case of a missing outcome value, due to dropout, the last observation was carried forward (LOCF analysis) for the qualitative analysis. Statistical analyses were performed using Statistical Package for the Social Sciences (SPSS), version 19. 


\section{RESULTS}

\subsection{Sample description}

The main sociodemographic and clinical variables of the study sample $(n=66)$ are summarized in Table 1.

The sample showed a mean age of $35.26 \pm 16.31$ years and a gender distribution of $36.4 \%$ men and $63.6 \%$ women. The mean DUI of the total sample was $36.70 \pm 66.35$ months, the mean age at illness onset was $35.26 \pm 16.31$ years and the mean duration of illness was 15.02 \pm .10 .42 years

Most common primary diagnoses were MDD (45.5\%) and BD (33.4\%), with an overall comorbidity rate of $48.5 \%$ in the overall sample. The $31.8 \%$ of the recruited patients reported at least one lifetime hospitalization.

Associated medications were present in the $89.4 \%$ of the total sample and remained stable across the follow up. Furthermore, the $87.9 \%$ of the patients had been previously treated with other antidepressants.

The total sample showed a mean vortioxetine daily dosage of $12.90 \pm 5.65 \mathrm{mg}$ (range 5-20 $\mathrm{mg})$, and the $33.3 \%(\mathrm{~N}=22)$ of the total sample could reach the highest dose of $20 \mathrm{mg} / \mathrm{day}$.

\subsection{Effectiveness}

Repeated measures ANOVA highlighted a significant improvement of HAM-D, MADRS, HAMA, YMRS and CGI-efficacy index across time (Table 2 and Figure 2a). No significant differences emerged from a comparison between groups of patients treated with different daily dosages of vortioxetine ( $\leq 10 \mathrm{mg}$ vs $>10 \mathrm{mg},<15 \mathrm{mg}$ vs $\geq 15 \mathrm{mg}, 20 \mathrm{mg}$ vs other dosage, 20 $\mathrm{mg}$ vs $\leq 10 \mathrm{mg}$ ), in terms of effectiveness (Table 2). However, a statistically non significant trend of association between increasing dosages of vortioxetine and higher improvements on psychometric scales was observed. Response and remission rates of $51.5 \%(\mathrm{~N}=34 / 57)$ and $36.4 \%(\mathrm{~N}=24 / 42)$, respectively, were found in the total sample, without any significant difference, comparing different groups of daily dosages (Table 3, Figure 2b).

\subsection{Tolerability}


Overall, $2 / 3$ of the total sample could tolerate vortioxetine without reporting any side effect. Indeed, side effects were reported by the $33.3 \%$ of the total sample: respectively represented by gastrointestinal side effects (mainly nausea, vomit and diarrhea) in the $72.7 \%$ of them and gastrointestinal side effects associated with other side effects (mainly headache and sweating) in the $22.7 \%$. of them. The main duration of side effects was $37.17 \pm 33.12$ days with moderate-severe $(72.8 \%)$ or mild $(27.3 \%)$ severity, measured through the DOTES and the TWIS. The association between reported side effects and vortioxetine was considered probable in the $90.9 \%$ of patients, remote or only possible in the rest of the sample on the basis of TWIS.

Comparative analyses did not show any differences in terms of tolerability across distinct groups (i.e. vortioxetine $\leq 10 \mathrm{mg}$ vs $>10 \mathrm{mg}$, dropout vs not, associated antidepressant vs not) and, therefore, were not reported.

\subsection{Dropout}

Overall two thirds of the total sample could complete the entire follow-up. Approximately $1 / 3$ of the total sample $(36.4 \%, \mathrm{~N}=24)$ dropped out, respectively $13.6 \%$ at $\mathrm{T} 1$ and $22.8 \%$ at $\mathrm{T} 2$. The reasons for dropout were: side effects (37.5\%), lack of efficacy (29.2\%), manic switch (12.5\%), more than one reason (12.5\%), others (e.g. personal decision, $8.3 \%$ ).

Therefore, in the $37.5 \%$ of the dropouts, treatment needed to be stopped because of low tolerability issues. These data are reported in Table 1 and represented in Figures $1 \mathrm{a}$ and $1 \mathrm{~b}$. Moreover, after splitting dropouts in two additional subgroups (at T1 and T2), it was found that most of patients dropping out at T1, discontinued for side effects $(62.5 \%)$, while, considering dropouts at T2, the main reason of discontinuation was lack of efficacy (37.5\%), followed by persistence of side effects $(25.0 \%)$. 


\section{DISCUSSION}

The present naturalistic study aimed to characterize effectiveness, tolerability and dropout rates of vortioxetine in a sample of patients with a MDE in the real world (e.g. with comorbidities and concomitant treatments).

\subsection{Effectiveness}

An overall significant improvement of HAM-D, MADRS, HAM-A, YMRS and CGI-efficacy index across time points was observed, in line with the available literature (Baldwin, Chrones, et al., 2016; Baldwin, Florea, Jacobsen, Zhong, \& Nomikos, 2016; Nomikos, Tomori, Zhong, Affinito, \& Palo, 2017). In particular, in a systematic review and network meta-analysis, comparing efficacy and acceptability of 21 antidepressant drugs, vortioxetine, together with agomelatine, amitriptyline, escitalopram, mirtazapine, paroxetine and venlafaxine were found to be more effective than other assessed antidepressants (Cipriani et al., 2018). However, studies specifically examining the effectiveness of vortioxetine in the real world are limited (Alvarez, Perez, Dragheim, Loft, \& Artigas, 2012; Baldwin, Loft, \& Dragheim, 2012; Boulenger, Loft, \& Olsen, 2014; Henigsberg, Mahableshwarkar, Jacobsen, Chen, \& Thase, 2012; Jain, Mahableshwarkar, Jacobsen, Chen, \& Thase, 2013; Katona, Hansen, \& Olsen, 2012; Mahableshwarkar, Jacobsen, \& Chen, 2013; Pae et al., 2015). Therefore, the specific purpose of the present study was to characterize the effectiveness profile of vortioxetine in a real world sample of patients with poly-comorbidity, poly-therapy, long duration of illness and previous exposure to other antidepressants.

In terms of vortioxetine dosage, no significant differences emerged from a comparison between groups of different dosages in relation to effectiveness and only a statistically non significant trend of association between increasing dosages of vortioxetine and higher improvements on psychometric scales was observed. Probably, the presence of polycomorbidity and poly-therapy in our sample could be the reason of this finding. Indeed, a metaanalysis of studies with vortioxetine (5-20 mg/day) showed a significant dose-relationship in 
the clinical effect, particularly for the overall increasing effect size associated with higher doses (Thase ME, Mahableshwarkar AR, Dragheim M, Loft H, 2016).

Such an effect could depend on the higher percentage of occupancy of the serotonin transporter (Areberg, Luntang-Jensen, Søgaard, \& Nilausen, 2012). On the other hand, the efficacy of vortioxetine at lower dosage $(5 \mathrm{mg})$ was supported by the trial in elderly patients with MDD (Katona et al., 2012), in particular in case of depressive symptoms associated with mild cognitive impairment (Cumbo, Cumbo, Torregrossa, \& Migliore, 2019). In addition, it could be hypothesized that, when other psychotropic drugs, particularly antidepressants, are associated with vortioxetine, like in the majority of our sample, lower dosages might be necessary to show clinical improvements. Furthermore, it could be hypothesized that the non significant trend of efficacy with higher dosages observed, could have become statistically significant with a larger sample.

\subsection{Tolerability}

Overall, two thirds of recruited patients did not report any side effects, while, in the other third, the $72.7 \%$ experimented gastrointestinal side effects (mainly nausea, vomit and diarrhea) and the $22.7 \%$ gastrointestinal ones associated with other side effects (mainly headache and sweating). Indeed, It is well established that vortioxetine's most common side effect is nausea (affecting more than 1 in 10 people) (EMA (European Medicines Agency), n.d.; Mclntyre, 2017), generally with mild or moderate severity related with high dosage and usually decreasing or extinguishing in few weeks (de Bartolomeis, Fagiolini, \& Maina, 2016). In the same direction, the duration of side effects, in the present study, slightly exceeded four weeks (37.17 \pm 33.12 days): conversely, the reported severity of side effects was moderate-severe (36.4\% moderate, $36.4 \%$ severe) and a worse tolerability was not associated with high doses of vortioxetine. Moreover, no weight gain emerged in our sample, in line with other published placebo-controlled trials and open label extension studies with vortioxetine (Baldwin, Chrones, et al., 2016). This aspect represents an important feature of this drug, for both young and elderly patients, avoiding negative metabolic effects and related reasons of treatment discontinuation (Salagre et al., n.d.). Furthermore, vortioxetine showed a favourable profile in 
terms of sexual side effects in the studied sample: only one patient (4.5\%) reported this specific side effect and we could not exclude that it was related to other concomitant treatment. Also in other studies with vortioxetine, sexual dysfunction rates were low (Baldwin, Chrones, et al., 2016; Mclntyre, 2017). Although in the present studies no significant differences among vortioxetine dosage groups were observed, in other trials, sexual dysfunction was found to be more frequent with higher doses, but always lower than those of Selective Serotonin Reuptake Inhibitors (SSRIs) (Jacobsen, Mahableshwarkar, Chen, Chrones, \& Clayton, 2015). Thus, switching treatment with SSRI to vortioxetine showed an important advantage for patients experiencing sexual dysfunction due to SSRIs (Jacobsen, Mahableshwarkar, Chen, et al., 2015). It represents a valuable feature of vortioxetine, since sexual side effects are very common among other antidepressants and often cause reduced adherence to treatment (Serretti \& Chiesa, 2009).

\subsection{Dropouts}

The overall literature found vortioxetine to be one of the most tolerable antidepressants, associated with the lowest rate of drop-out (Cipriani et al., 2018). In our sample, approximately one third (36.4\%, N=24) dropped out. In particular, most patients dropping out at $\mathrm{T} 1$ discontinued for side effects $(62.5 \%, \mathrm{~N}=5)$, probably because they could not reach $\mathrm{T} 2$ for the impacting side effects: on the other hand, considering dropouts at $\mathrm{T} 2$, the main reason of discontinuation was the lack of efficacy $(37.5 \%, \mathrm{~N}=6)$ and, secondly, the persistence of side effects $(25.0 \%, \mathrm{~N}=4)$. The possible explanation could be that subjects who reached $\mathrm{T} 2$ without a full response to vortioxetine, discontinued for the persistence of depressive symptoms. Our study could not investigate whether a slow titration (i.e. through drops) of vortioxetine could have reduced the rate of dropouts, due to side effects, and ultimately increased the rate of patients completing the entire follow-up.

\subsection{Limitations}

In the present study some limitations should be taken into account in the interpretation of the aforementioned findings. First, the limited recruited study sample, then the following methodological limitations should be considered. For example, referring to collected socio- 
demographic and clinical variables, the presence of recall bias cannot be excluded, particularly for patients with most remote onset, as well as the retrospective collection bias from previous medical charts. Moreover, our sample showed different illness severities and most of patients had previously been exposed to other antidepressants. Furthermore, the presence of polycomorbidities (both medical and psychiatric), concomitant treatments in the majority of the sample and different dosages of vortioxetine and /or different regimens in terms of unique versus multiple daily administration and finally a different titration process, might have ultimately conditioned the vortioxetine efficacy as well as the onset of side effects and dropout rates.

\section{CONCLUSION}

In conclusion, the present report confirms vortioxetine's effectiveness over affective symptoms, along with a favorable tolerability profile and low dropout rates, independently from daily dosages, in a sample of patients with poly-comorbidities and poly-therapy.

In order to assess whether higher dosages of vortioxetine can determine a larger quantitative and qualitative responses, maintaining a favorable tolerability profile, larger samples and further studies are warranted in the real world, including patients with poly-comorbidity, polytherapy, long duration of illness and previous exposure to other antidepressants. 
TABLES

Table 1. Main socio-demographic and clinical features of the study sample and profile of vortioxetine tolerability.

\begin{tabular}{|c|c|c|c|c|c|}
\hline \multicolumn{6}{|c|}{ Total sample $\mathrm{N}=66$} \\
\hline \multirow{2}{*}{ Gender } & Male & $36.4 \%(\mathrm{~N}=24)$ & \multirow{4}{*}{$\begin{array}{c}\text { Associated } \\
\text { therapy* }\end{array}$} & Antidepressants yes/no & $33.3 \%(\mathrm{~N}=22)$ \\
\hline & Female & $63.6 \%(\mathrm{~N}=42)$ & & Stabilizers yes/no & $54.5 \%(\mathrm{~N}=36)$ \\
\hline Age & \multicolumn{2}{|c|}{$50.20 \pm 15.81$} & & Benzodiazepinesyes/no & $37.9 \%(\mathrm{~N}=25)$ \\
\hline Age at onset & \multicolumn{2}{|c|}{$35.26 \pm 16.31$} & & Antipsychotics yes/no & $51.5 \%(\mathrm{~N}=34)$ \\
\hline \multirow{6}{*}{$\begin{array}{l}\text { Vortioxetine } \\
\text { dosage }\end{array}$} & \multicolumn{2}{|c|}{$12.9 \pm 5.65$} & \multirow{2}{*}{ Side effects (SE) } & Yes & $33.3 \%(\mathrm{~N}=22)$ \\
\hline & $20 \mathrm{mg}$ & $33.3 \%(\mathrm{~N}=22)$ & & No & $66.7 \%(\mathrm{~N}=44)$ \\
\hline & $<15 \mathrm{mg}$ & $57.58 \%(\mathrm{~N}=38)$ & SE duration & \multicolumn{2}{|c|}{$37.17 \pm 33.12$ days } \\
\hline & $\geq 15 \mathrm{mg}$ & $42.42 \%(\mathrm{~N}=28)$ & \multirow{3}{*}{$\begin{array}{c}\text { SE association } \\
\text { (DOTES- } \\
\text { TWIS) } \\
\end{array}$} & Remote & $4.5 \%(\mathrm{~N}=1)$ \\
\hline & $\leq 10 \mathrm{mg}$ & $56.1 \%(\mathrm{~N}=37)$ & & Possibile & $4.5 \%(\mathrm{~N}=1)$ \\
\hline & $>10 \mathrm{mg}$ & $43.9 \%(\mathrm{~N}=29)$ & & Probable & $90.9 \%(\mathrm{~N}=20)$ \\
\hline \multirow{8}{*}{$\begin{array}{c}\text { Psychiatric } \\
\text { primary diagnosis }\end{array}$} & MDD & $45.5 \%(\mathrm{~N}=30)$ & \multirow{3}{*}{ SE severity } & Mild & $27.3 \%(\mathrm{~N}=6)$ \\
\hline & BD 1 & $7.6 \%(\mathrm{~N}=5)$ & & Moderate & $36.4 \%(\mathrm{~N}=8)$ \\
\hline & BD 2 & $25.8 \%(\mathrm{~N}=17)$ & & Severe & $36.4 \%(\mathrm{~N}=8)$ \\
\hline & GAD & $7.6 \%(\mathrm{~N}=5)$ & \multirow{3}{*}{ Type of SE ** } & Gastrointestinal(GI) & $72.7 \%(\mathrm{~N}=16)$ \\
\hline & PD & $3.0 \%(\mathrm{~N}=2)$ & & $\downarrow$ Libido & $4.5 \%(\mathrm{~N}=1)$ \\
\hline & OCD & $4.5 \%(\mathrm{~N}=3)$ & & GI + other & $22.7 \%(\mathrm{~N}=5)$ \\
\hline & PerD & $1.5 \%(\mathrm{~N}=1)$ & \multirow{2}{*}{ Dropout } & Yes & $36.4 \%(\mathrm{~N}=24)$ \\
\hline & Other & $4.5 \%(\mathrm{~N}=3)$ & & No & $63.6 \%(\mathrm{~N}=42)$ \\
\hline \multirow{2}{*}{$\begin{array}{c}\text { Psychiatric family } \\
\text { history }\end{array}$} & Yes & $62.1 \%(\mathrm{~N}=41)$ & \multirow{5}{*}{$\begin{array}{c}\text { Reasons of } \\
\text { dropout }\end{array}$} & Side effects & $37.5 \%(\mathrm{~N}=9)$ \\
\hline & No & $37.9 \%(\mathrm{~N}=25)$ & & Non efficacy & $29.2 \%(\mathrm{~N}=7)$ \\
\hline \multirow{2}{*}{$\begin{array}{c}\text { Psychiatric } \\
\text { comorbidities }\end{array}$} & Yes & $48.5 \%(\mathrm{~N}=32)$ & & Manic switch & $12.5 \%(\mathrm{~N}=3)$ \\
\hline & No & $51.5 \%(\mathrm{~N}=34)$ & & Others & $8.3 \%(\mathrm{~N}=2)$ \\
\hline \multirow{2}{*}{$\begin{array}{c}\text { Medical } \\
\text { comorbidity }\end{array}$} & Yes & $62.1 \%(\mathrm{~N}=41)$ & & $>1$ reason & $12.5 \%(\mathrm{~N}=3)$ \\
\hline & No & $37.9 \%(\mathrm{~N}=25)$ & DUI & \multicolumn{2}{|c|}{$36.70 \pm 66.35$} \\
\hline \multirow{2}{*}{ Hospitalization } & Yes & $31.8 \%(\mathrm{~N}=21)$ & \multirow{2}{*}{$\begin{array}{c}\text { Previous } \\
\text { antidepressant }\end{array}$} & Yes & $87.9 \%(\mathrm{~N}=58)$ \\
\hline & No & $68.2 \%(\mathrm{~N}=45)$ & & No & $12.1 \%(\mathrm{~N}=8)$ \\
\hline Response rate*** & \multicolumn{2}{|c|}{$51.5 \%(\mathrm{~N}=34)$} & \multirow{2}{*}{$\begin{array}{c}\text { Duration of } \\
\text { illness (years) }\end{array}$} & \multirow{2}{*}{\multicolumn{2}{|c|}{$15.02 \pm .10 .42$}} \\
\hline Remission rate*** & \multicolumn{2}{|c|}{$36.4 \%(\mathrm{~N}=24)$} & & & \\
\hline
\end{tabular}

*the total percentage could exceed 100, because the same patient could have different associated treatments.

** Percentages are related to the total of 22 patients reporting side effects (33.3\% of the total sample).

*** Dropouts at T1 were not taken into account for statistical analysis related to remission rates, while dropouts both at T1 and T2 were excluded for analysis on response rate.

Values are represented as mean \pm SD.

$\mathrm{MDD}=$ major depressive disorder, $\mathrm{BD}=$ bipolar disorder, $\mathrm{GAD}=$ generalized anxiety disorder, $\mathrm{PD}=$ panic disorder, $\mathrm{OCD}=$ obsessive compulsive disorder, $\mathrm{PerD}=$ personality disorders, $\mathrm{SE}=$ side effects, $\mathrm{DUI}=$ duration of untreated illness. 
Table 2. Psychometric evaluation across time points for the total sample and different dosage subgroups.

\begin{tabular}{|c|c|c|c|c|c|c|}
\hline & & & T0 & T1 & T2 & $\mathbf{P}$ \\
\hline \multirow{11}{*}{ HAMD } & Total sample & $\mathrm{N}=66$ & $20.17 \pm 5.77$ & $15.55 \pm 6.17$ & $11.30 \pm 7.10$ & 0.000 \\
\hline & Vortioxetine $\leq 10 \mathrm{mg}$ & $\mathrm{N}=37$ & $20.68 \pm 5.83$ & $15.22 \pm 6.12$ & $11.30 \pm 7.67$ & \multirow{2}{*}{0.947} \\
\hline & Vortioxetine $>10 \mathrm{mg}$ & $\mathrm{N}=29$ & $19.52 \pm 5.74$ & $15.97 \pm 6.32$ & $11.31 \pm 6.43$ & \\
\hline & Vortioxetine $<15 \mathrm{mg}$ & $\mathrm{N}=38$ & $20.53 \pm 5.82$ & $15.37 \pm 6.11$ & $11.55 \pm 7.72$ & \multirow{2}{*}{0.688} \\
\hline & Vortioxetine $\geq 15 \mathrm{mg}$ & $\mathrm{N}=28$ & $19.68 \pm 5.77$ & $16.00 \pm 6.43$ & $11.18 \pm 6.50$ & \\
\hline & Vortioxetine $20 \mathrm{mg}$ & $\mathrm{N}=22$ & $18.68 \pm 3.90$ & $14.77 \pm 4.05$ & $9.95 \pm 5.69$ & \multirow{2}{*}{0.693} \\
\hline & Vortioxetine $<20 \mathrm{mg}$ & $\mathrm{N}=44$ & $20.91 \pm 5.77$ & $16.07 \pm 7.04$ & $12.11 \pm 78$ & \\
\hline & Vortioxetine $20 \mathrm{mg}$ & $\mathrm{N}=22$ & $18.68 \pm 3.90$ & $14.77 \pm 4.05$ & $9.95 \pm 5.69$ & \multirow{2}{*}{0.683} \\
\hline & Vortioxetine $\leq 10 \mathrm{mg}$ & $\mathrm{N}=37$ & $20.68 \pm 5.83$ & $15.38 \pm 6.19$ & $11.46 \pm 7.81$ & \\
\hline & Vortioxetine $=$ single AD & $\mathrm{N}=44$ & $20.39 \pm 6.19$ & $16.25 \pm 4.47$ & $11.73 \pm 7.31$ & \multirow{2}{*}{0.692} \\
\hline & Vortioxetine+other AD & $\mathrm{N}=22$ & $19.73 \pm 4.94$ & $14.41 \pm 5.57$ & $10.73 \pm 7.05$ & \\
\hline \multirow{11}{*}{ MADRS } & Total sample & $\mathrm{N}=66$ & $24.53 \pm 5.71$ & $19.50 \pm 6.35$ & $14.88 \pm 7.64$ & 0.000 \\
\hline & Vortioxetine $\leq 10 \mathrm{mg}$ & $\mathrm{N}=37$ & $24.59 \pm 5.97$ & $18.54 \pm 6.44$ & $14.24 \pm 8.08$ & \multirow{2}{*}{0.714} \\
\hline & Vortioxetine $>10 \mathrm{mg}$ & $N=29$ & $24.45 \pm 5.46$ & $20.72 \pm 6.11$ & $15.69 \pm 7.10$ & \\
\hline & Vortioxetine $<15 \mathrm{mg}$ & $\mathrm{N}=38$ & $24.55 \pm 5.90$ & $18.63 \pm 6.38$ & $14.45 \pm 8.07$ & \multirow{2}{*}{0.713} \\
\hline & Vortioxetine $\geq 15 \mathrm{mg}$ & $\mathrm{N}=28$ & $24.53 \pm 5.71$ & $20.68 \pm 6.22$ & $15.46 \pm 7.12$ & \\
\hline & Vortioxetine $20 \mathrm{mg}$ & $\mathrm{N}=22$ & $23.73 \pm 4.10$ & $19.68 \pm 4.28$ & $14.23 \pm 6.82$ & \multirow{2}{*}{0.717} \\
\hline & Vortioxetine $<20 \mathrm{mg}$ & $\mathrm{N}=44$ & $24.53 \pm 6.37$ & $19.41 \pm 7.20$ & $15.20 \pm 8.08$ & \\
\hline & Vortioxetine $20 \mathrm{mg}$ & $\mathrm{N}=22$ & $23.73 \pm 4.10$ & $19.68 \pm 4.28$ & $14.23 \pm 6.82$ & \multirow{2}{*}{0.708} \\
\hline & Vortioxetine $\leq 10 \mathrm{mg}$ & $\mathrm{N}=37$ & $24.59 \pm 5.97$ & $18.54 \pm 6.44$ & $14.24 \pm 8.08$ & \\
\hline & Vortioxetine $=$ single AD & $\mathrm{N}=44$ & $24.98 \pm 5.94$ & $20.48 \pm 6.32$ & $15.39 \pm 7.91$ & \multirow{2}{*}{0.715} \\
\hline & Vortioxetine+other AD & $\mathrm{N}=22$ & $23.64 \pm 5.22$ & $17.55 \pm 6.06$ & $13.86 \pm 7.15$ & \\
\hline \multirow{11}{*}{ HАMA } & Total sample & $\mathrm{N}=66$ & $14.83 \pm 5.27$ & $11.65 \pm 5.26$ & $8.62 \pm 5.62$ & 0.000 \\
\hline & Vortioxetine $\leq 10 \mathrm{mg}$ & $\mathrm{N}=37$ & $14.86 \pm 5.38$ & $11.32 \pm 5.01$ & $8.46 \pm 5.87$ & \multirow{2}{*}{0.761} \\
\hline & Vortioxetine $>10 \mathrm{mg}$ & $\mathrm{N}=29$ & $14.79 \pm 5.22$ & $12.07 \pm 5.62$ & $8.83 \pm 5.38$ & \\
\hline & Vortioxetine $<15 \mathrm{mg}$ & $\mathrm{N}=38$ & $14.76 \pm 5.35$ & $11.32 \pm 4.94$ & $8.53 \pm 5.81$ & \multirow{2}{*}{0.729} \\
\hline & Vortioxetine $\geq 15 \mathrm{mg}$ & $\mathrm{N}=28$ & $14.93 \pm 5.27$ & $12.11 \pm 5.72$ & $8.75 \pm 5.46$ & \\
\hline & Vortioxetine $20 \mathrm{mg}$ & $\mathrm{N}=22$ & $14.00 \pm 4.45$ & $10.82 \pm 4.48$ & $7.59 \pm 4.62$ & \multirow{2}{*}{0.732} \\
\hline & Vortioxetine $<20 \mathrm{mg}$ & $\mathrm{N}=44$ & $15.25 \pm 5.64$ & $12.07 \pm 5.61$ & $9.14 \pm 6.05$ & \\
\hline & Vortioxetine $20 \mathrm{mg}$ & $\mathrm{N}=22$ & $14.00 \pm 4.45$ & $10.82 \pm 4.48$ & $7.59 \pm 4.62$ & \multirow{2}{*}{0.726} \\
\hline & Vortioxetine $\leq 10 \mathrm{mg}$ & $\mathrm{N}=37$ & $14.86 \pm 5.38$ & $11.32 \pm 5.01$ & $8.46 \pm 5.87$ & \\
\hline & Vortioxetine $=$ single AD & $\mathrm{N}=44$ & $15.25 \pm 5.45$ & $12.23 \pm 5.37$ & $8.84 \pm 5.54$ & \multirow{2}{*}{0.729} \\
\hline & Vortioxetine+other AD & $\mathrm{N}=22$ & $14.00 \pm 4.91$ & $10.50 \pm 4.95$ & $8.18 \pm 5.89$ & \\
\hline & Total sample & $\mathrm{N}=66$ & $2.65 \pm 1.52$ & $2.27 \pm 1.87$ & $1.71 \pm 1.92$ & 0.000 \\
\hline & Vortioxetine $\leq 10 \mathrm{mg}$ & $\mathrm{N}=37$ & $2.76 \pm 1.55$ & $2.38 \pm 2.11$ & $1.78 \pm 2.25$ & 0076 \\
\hline & Vortioxetine $>10 \mathrm{mg}$ & $\mathrm{N}=29$ & $2.52 \pm 1.50$ & $2.14 \pm 1.53$ & $1.62 \pm 1.43$ & $0.9 / 6$ \\
\hline & Vortioxetine $<15 \mathrm{mg}$ & $\mathrm{N}=38$ & $2.68 \pm 1.60$ & $2.32 \pm 2.12$ & $1.74 \pm 2.24$ & \\
\hline & Vortioxetine $\geq 15 \mathrm{mg}$ & $\mathrm{N}=28$ & $2.61 \pm 1.45$ & $2.21 \pm 1.50$ & $1.75 \pm 1.38$ & 0.729 \\
\hline YMRS & Vortioxetine $20 \mathrm{mg}$ & $\mathrm{N}=22$ & $2.58 \pm 1.37$ & $2.18 \pm 1.47$ & $1.73 \pm 1.39$ & \\
\hline & Vortioxetine $<20 \mathrm{mg}$ & $\mathrm{N}=44$ & $2.68 \pm 1.61$ & $2.32 \pm 2.06$ & $1.75 \pm 1.14$ & 0.729 \\
\hline & Vortioxetine $20 \mathrm{mg}$ & $\mathrm{N}=22$ & $2.58 \pm 1.37$ & $2.18 \pm 1.47$ & $1.73 \pm 1.39$ & 0721 \\
\hline & Vortioxetine $\leq 10 \mathrm{mg}$ & $\mathrm{N}=37$ & $2.76 \pm 1.55$ & $2.38 \pm 2.11$ & $1.78 \pm 2.25$ & 0.721 \\
\hline & Vortioxetine $=$ single AD & $\mathrm{N}=44$ & $2.77 \pm 1.61$ & $2.50 \pm 2.11$ & $1.98 \pm 2.18$ & \\
\hline & Vortioxetine+other AD & $\mathrm{N}=22$ & $2.41 \pm 1.33$ & $1.82 \pm 1.18$ & $1.27 \pm 1.08$ & 0.732 \\
\hline & Total sample & $\mathrm{N}=66$ & - & $\mathbf{1 . 7 5} \pm 1.19$ & $2.35 \pm 1.58$ & $\mathbf{0 . 0 0 0}$ \\
\hline & Vortioxetine $\leq 10 \mathrm{mg}$ & $\mathrm{N}=37$ & - & $1.74 \pm 1.34$ & $2.32 \pm 1.68$ & 0972 \\
\hline & Vortioxetine $>10 \mathrm{mg}$ & $\mathrm{N}=29$ & - & $1.75 \pm 0.99$ & $2.39 \pm 1.48$ & 0.913 \\
\hline & Vortioxetine $<15 \mathrm{mg}$ & $\mathrm{N}=38$ & - & $1.72 \pm 1.32$ & $1.77 \pm 0.99$ & \\
\hline CGI - & Vortioxetine $\geq 15 \mathrm{mg}$ & $\mathrm{N}=28$ & - & $2.29 \pm 1.67$ & $2.48 \pm 1.48$ & 0.803 \\
\hline Efficacy & Vortioxetine $20 \mathrm{mg}$ & $\mathrm{N}=22$ & - & $1.91 \pm 0.97$ & $2.64 \pm 1.43$ & 0806 \\
\hline Index & Vortioxetine $<20 \mathrm{mg}$ & $\mathrm{N}=44$ & - & $1.66 \pm 1.29$ & $2.24 \pm 1.65$ & 0.806 \\
\hline & Vortioxetine $20 \mathrm{mg}$ & $\mathrm{N}=22$ & - & $1.91 \pm 0.97$ & $2.64 \pm 1.43$ & 0830 \\
\hline & Vortioxetine $\leq 10 \mathrm{mg}$ & $\mathrm{N}=37$ & - & $1.74 \pm 1.34$ & $2.32 \pm 1.68$ & 0.830 \\
\hline & Vortioxetine $=$ single AD & $\mathrm{N}=44$ & - & $1.75 \pm 1.15$ & $2.41 \pm 1.57$ & \\
\hline & Vortioxetine+other AD & $\mathrm{N}=22$ & - & $1.74 \pm 1.28$ & $2.29 \pm 1.64$ & 0.802 \\
\hline
\end{tabular}

$\mathrm{T} 0=$ when vortioxetine was started, $\mathrm{T} 1=$ after four weeks, $\mathrm{T} 2=$ after 3 months. HAM-D $=$ Hamilton Depression Rating Scale, MADRS = Montgomery-Asberg Depression Rating Scale, HAM-A = Hamilton Anxiety Rating Scale, YMRS = Young Mania Rating Scale, CGI-Efficacy Index = Clinical Global Impression-Efficacy Index. "Vortioxetine=single AD": patients treated with vortioxetine as single antidepressant (in association with other psychopharmacological class or not). "Vortioxetine+other AD": patients treated with vortioxetine together with other antidepressants (in association with other psychopharmacological class or not). 
Table 3. Response and remission rates in the total sample and comparing different dosage subgroups

\begin{tabular}{|c|c|c|}
\hline & \multicolumn{2}{|c|}{ Total sample } \\
\hline Response & \multicolumn{2}{|c|}{$51.5 \%(\mathrm{~N}=34 / 57)$} \\
\hline Remission & \multicolumn{2}{|c|}{$36.4 \%(\mathrm{~N}=24 / 42)$} \\
\hline & Vortioxetine 20mg & Vortioxetine $\leq 10 \mathrm{mg}$ \\
\hline Response yes & $60.0 \%(\mathrm{~N}=12, \mathrm{tot}=20)$ & $66.7 \%(\mathrm{~N}=20, \mathrm{tot}=30)$ \\
\hline Response no & $40.0 \%(\mathrm{~N}=8$, tot $=20)$ & $33.3 \%(\mathrm{~N}=10$, tot $=30)$ \\
\hline Remission yes & $58.8 \%(\mathrm{~N}=10$, tot $=17)$ & $66.7 \%(\mathrm{~N}=14, \mathrm{tot}=21)$ \\
\hline \multirow[t]{2}{*}{ Remission no } & $41.2 \%(\mathrm{~N}=7$, tot $=17)$ & $33.3 \%(\mathrm{~N}=7$, tot $=21)$ \\
\hline & Vortioxetine 20 mg & Vortioxetine $<20 \mathrm{mg}$ \\
\hline Response yes & $60.0 \%(\mathrm{~N}=12, \mathrm{tot}=20)$ & $59.5 \%(\mathrm{~N}=22$, tot $=37)$ \\
\hline Response no & $40.0 \%(\mathrm{~N}=8$, tot $=20)$ & $40.5 \%(\mathrm{~N}=15, \mathrm{tot}=37)$ \\
\hline Remission yes & $58.8 \%(\mathrm{~N}=10$, tot $=17)$ & $56.0 \%(\mathrm{~N}=14$, tot $=25)$ \\
\hline \multirow{2}{*}{ Remission no } & $41.2 \%(\mathrm{~N}=7, \mathrm{tot}=17)$ & $44.0 \%(\mathrm{~N}=11, \mathrm{tot}=25)$ \\
\hline & Vortioxetine $\geq 15 \mathrm{mg}$ & Vortioxetine $<15 \mathrm{mg}$ \\
\hline Response yes & $53.8 \%(\mathrm{~N}=14$, tot $=26)$ & $64.5 \%(\mathrm{~N}=20$, tot $=31)$ \\
\hline Response no & $46.2 \%(\mathrm{~N}=12, \mathrm{tot}=26)$ & $35.5 \%(\mathrm{~N}=11, \mathrm{tot}=31)$ \\
\hline Remission yes & $47.6 \%(\mathrm{~N}=10, \mathrm{tot}=21)$ & $66.7 \%(\mathrm{~N}=14, \mathrm{tot}=21)$ \\
\hline \multirow[t]{2}{*}{ Remission no } & $52.4 \%(\mathrm{~N}=11, \mathrm{tot}=21)$ & $33.3 \%(\mathrm{~N}=7$, tot $=21)$ \\
\hline & Vortioxetine $>10 \mathrm{mg}$ & Vortioxetine $\leq 10 \mathrm{mg}$ \\
\hline Response yes & $51.9 \%(\mathrm{~N}=14$, tot $=27)$ & $66.7 \%(\mathrm{~N}=20$, tot $=30)$ \\
\hline Response no & $48.1 \%(\mathrm{~N}=13, \mathrm{tot}=27)$ & $33.3 \%(\mathrm{~N}=10$, tot $=30)$ \\
\hline Remission yes & $47.6 \%(\mathrm{~N}=10$, tot $=21)$ & $66.7 \%(\mathrm{~N}=14, \mathrm{tot}=21)$ \\
\hline Remission no & $52.4 \%(\mathrm{~N}=11, \mathrm{tot}=21)$ & $33.3 \%(\mathrm{~N}=7$, tot $=21)$ \\
\hline
\end{tabular}

Dropouts at T2 were not taken into account for statistical analysis related to remission rates (percentage referred to 57 patients completing the entire follow-up), while dropouts at T1 were excluded for analysis on response rate (percentage referred to 42 patients completing at least the T1 evaluation). 


\section{FIGURES}

Figure 1. a) Side effects rate and type of side effects; b) Drop out rate and reasons of drop out.

1a) Side effects rate and type of side effects

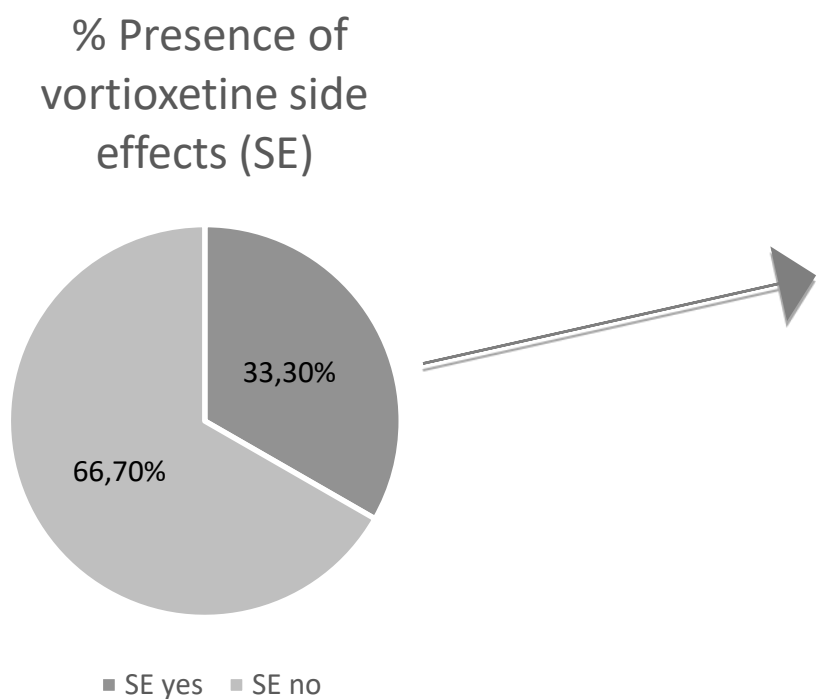

$\%$ Type of side effects (SE)

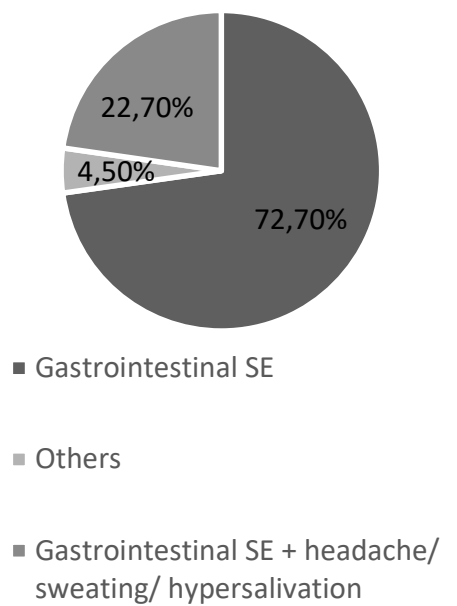

(\% referred to the total sample $(\mathrm{N}=66)$ )

(\% referred to subjects reporting side effects $(\mathrm{N}=22)$ )

1b) Drop out rate and reasons of drop out

\% Drop out (DO) from treatment with

Vortioxetine

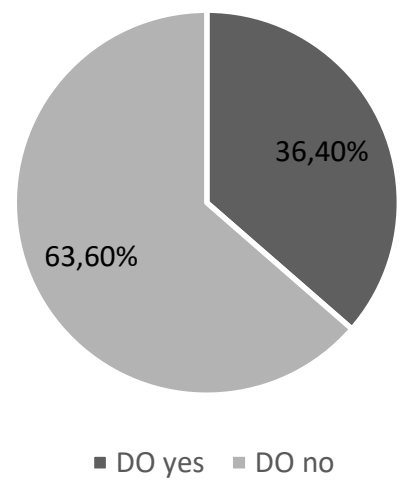

(\% referred to the total sample $(\mathrm{N}=66)$ )
\% Reason of drop out (DO)

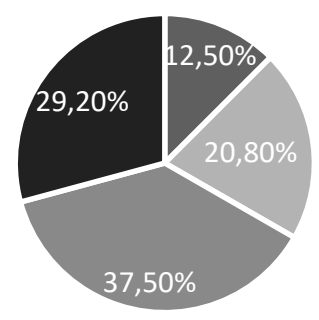

- Manic switch

- Other reasons/ $\geq 1$ reason

- Side effects

- Lack of efficacy /partial remission

(\% referred to drop out $(\mathrm{N}=24)$ ) 
Figure 2. Results of quantitative and qualitative analysis.

2a) Psychometric evaluations across time points for the total sample

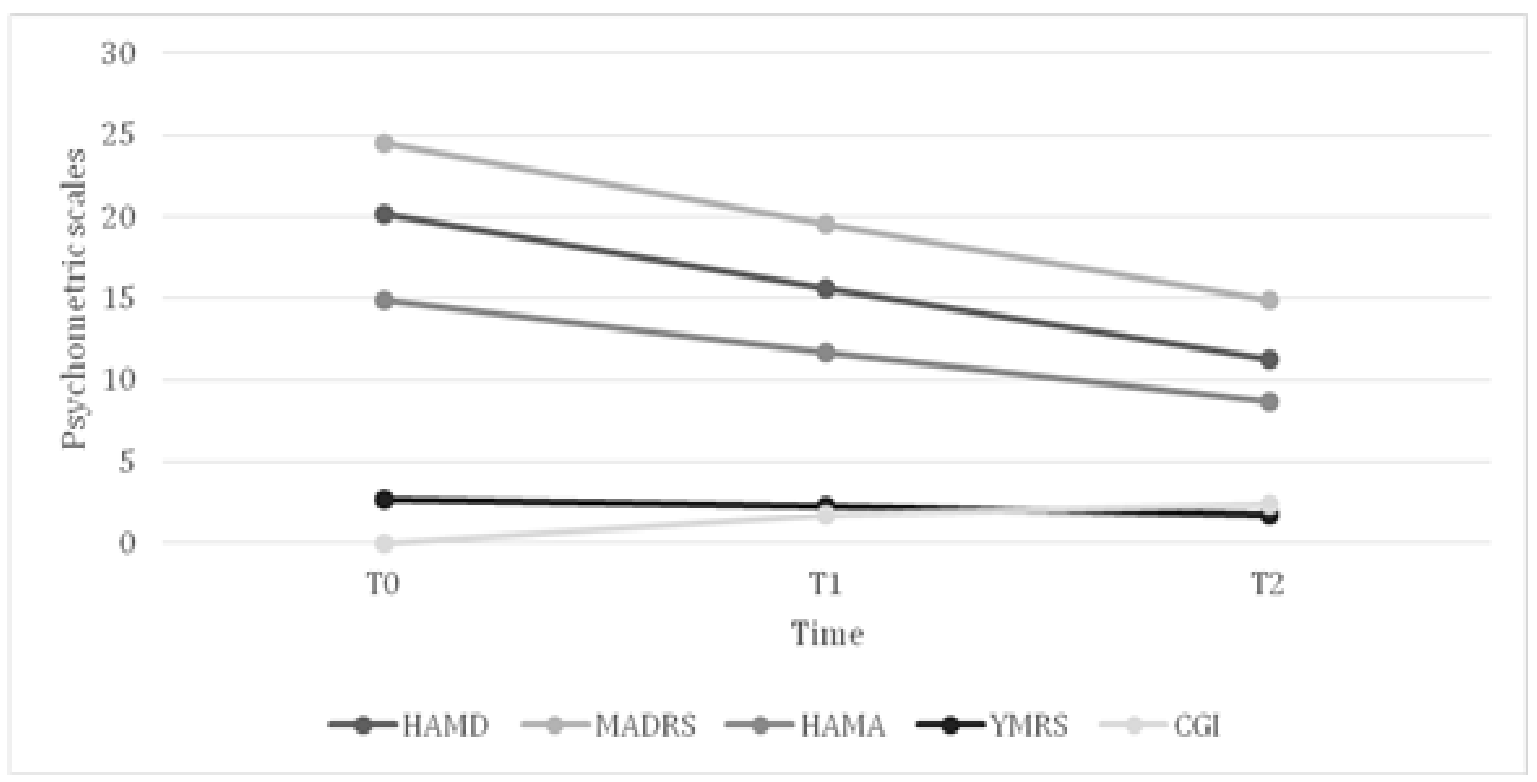

$\mathrm{T} 0=$ when vortioxetine was started, $\mathrm{T} 1=$ after four weeks, $\mathrm{T} 2=$ after 3 months. HAM-D = Hamilton Depression Rating Scale, MADRS = Montgomery-Asberg Depression Rating Scale, HAM-A = Hamilton Anxiety Rating Scale, YMRS = Young Mania Rating Scale, CGI-Efficacy Index = Clinical Global Impression-Efficacy Index

\section{2b) Remission and response rates in the total sample.}

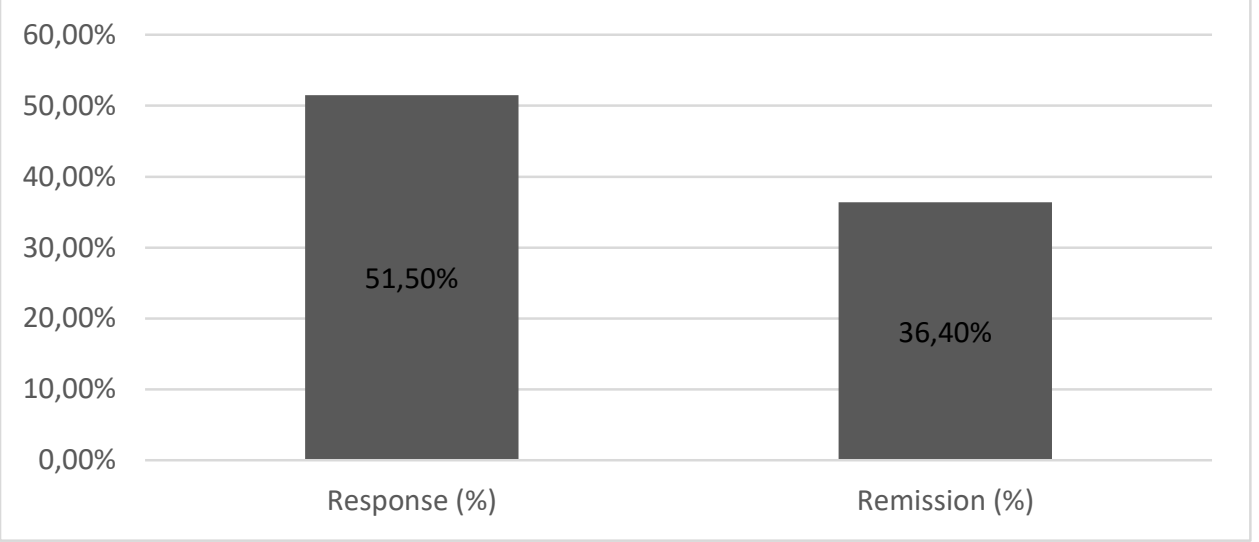

Dropouts at T2 were not taken into account for statistical analysis related to remission rates, while dropouts at T1 were excluded for analysis on response rate. Remission percentage is referred to the 42 patients who completed T2 evaluations, while response percentage is referred to the 57 patients who completed at least T1 evaluations. 


\section{Contributors}

All authors contributed to and have approved the final manuscript.

\section{Acknowledgements}

We acknowledge the advice from all contributors of the present naturalistic study.

\section{Conflict of Interest and Source of Funding:}

-Vera De Carlo, Benedetta Grancini, Matteo Vismara, Anna Colombo report no financial relationships with commercial interests.

-Benatti Beatrice has received a consultant fee from Lundbeck

-Bosi Monica Francesca has received a speaker fees from Lundbeck

- Viganò Caterina Adele has received speaker fees from Lundbeck and Angelini

-Prof. Dell'Osso has received lecture honoraria from Angelini, Jansen, Lundbeck, Livanova, Arcapharma, Neuraxpharm.

The present study was conducted according to the principles expressed in the Declaration of Helsinki. 


\section{REFERENCES}

Alam, M. Y., Jacobsen, P. L., Chen, Y., Serenko, M., \& Mahableshwarkar, A. R. (2014). Safety, tolerability, and efficacy of vortioxetine (Lu AA21004) in major depressive disorder: Results of an open-label, flexible-dose, 52-week extension study. International Clinical Psychopharmacology, 29(1), 36-44. https://doi.org/10.1097/YIC.0000000000000010

Alvarez, E., Perez, V., Dragheim, M., Loft, H., \& Artigas, F. (2012). A double-blind, randomized, placebo-controlled, active reference study of Lu AA21004 in patients with major depressive disorder. The International Journal of Neuropsychopharmacology, 15(5), 589-600. https://doi.org/10.1017/S1461145711001027

APA American Psychiatric. (2013). Diagnostic and Statistical Manual, 5th edition.

Areberg, J., Luntang-Jensen, M., Søgaard, B., \& Nilausen, D. Ø. (2012). Occupancy of the serotonin transporter after administration of Lu AA21004 and its relation to plasma concentration in healthy subjects. Basic \& Clinical Pharmacology \& Toxicology, 110(4), 401-404. https://doi.org/10.1111/j.1742-7843.2011.00810.x

Baldwin, D. S., Chrones, L., Florea, I., Nielsen, R., Nomikos, G. G., Palo, W., \& Reines, E. (2016). The safety and tolerability of vortioxetine: Analysis of data from randomized placebo-controlled trials and open-label extension studies. Journal of Psychopharmacology (Oxford, England), 30(3), 242-252. https://doi.org/10.1177/0269881116628440

Baldwin, D. S., Florea, I., Jacobsen, P. L., Zhong, W., \& Nomikos, G. G. (2016). A metaanalysis of the efficacy of vortioxetine in patients with major depressive disorder (MDD) and high levels of anxiety symptoms. Journal of Affective Disorders, 206, 140-150. https://doi.org/10.1016/j.jad.2016.07.015

Baldwin, D. S., Hansen, T., \& Florea, I. (2012). Vortioxetine (Lu AA21004) in the long-term open-label treatment of major depressive disorder. Current Medical Research and Opinion, 28(10), 1717-1724. https://doi.org/10.1185/03007995.2012.725035

Baldwin, D. S., Loft, H., \& Dragheim, M. (2012). A randomised, double-blind, placebo controlled, duloxetine-referenced, fixed-dose study of three dosages of Lu AA21004 in acute treatment of major depressive disorder (MDD). European Neuropsychopharmacology: The Journal of the European College of Neuropsychopharmacology, 22(7), 482-491. https://doi.org/10.1016/j.euroneuro.2011.11.008

Bang-Andersen, B., Ruhland, T., Jørgensen, M., Smith, G., Frederiksen, K., Jensen, K. G., ... Stensbøl, T. B. (2011). Discovery of 1-[2-(2,4dimethylphenylsulfanyl)phenyl]piperazine (Lu AA21004): a novel multimodal compound for the treatment of major depressive disorder. Journal of Medicinal Chemistry, 54(9), 3206-3221. https://doi.org/10.1021/jm101459g

Bauer, M., Pfennig, A., Severus, E., Whybrow, P. C., Angst, J., Möller, H.-J., \& World Federation of Societies of Biological Psychiatry. Task Force on Unipolar Depressive Disorders. (2013). World Federation of Societies of Biological Psychiatry (WFSBP) guidelines for biological treatment of unipolar depressive disorders, part 1: update 2013 on the acute and continuation treatment of unipolar depressive disorders. The World Journal of Biological Psychiatry: The Official Journal of the World Federation of Societies of Biological Psychiatry, 14(5), 334-385. https://doi.org/10.3109/15622975.2013.804195

Berhan, A., \& Barker, A. (2014). Vortioxetine in the treatment of adult patients with major depressive disorder: a meta-analysis of randomized double-blind controlled trials. BMC Psychiatry, 14, 276. https://doi.org/10.1186/s12888-014-0276-x

Boulenger, J.-P., Loft, H., \& Olsen, C. K. (2014). Efficacy and safety of vortioxetine (Lu AA21004), 15 and $20 \mathrm{mg} /$ day: a randomized, double-blind, placebo-controlled, duloxetine-referenced study in the acute treatment of adult patients with major depressive disorder. International Clinical Psychopharmacology, 29(3), 138-149. 
https://doi.org/10.1097/YIC.0000000000000018

Charara, R., Forouzanfar, M., Naghavi, M., Moradi-Lakeh, M., Afshin, A., Vos, T., ... Mokdad, A. H. (2017). The Burden of Mental Disorders in the Eastern Mediterranean Region, 1990-2013. PLOS ONE, 12(1), e0169575. https://doi.org/10.1371/journal.pone.0169575

Cipriani, A., Furukawa, T. A., Salanti, G., Chaimani, A., Atkinson, L. Z., Ogawa, Y., ... Geddes, J. R. (2018). Comparative efficacy and acceptability of 21 antidepressant drugs for the acute treatment of adults with major depressive disorder: a systematic review and network meta-analysis. The Lancet, 391(10128), 1357-1366. https://doi.org/10.1016/S0140-6736(17)32802-7

Corruble, E., \& Guelfi, J. D. (n.d.). Pain complaints in depressed inpatients. Psychopathology, 33(6), 307-309. https://doi.org/10.1159/000029163

Cumbo, E., Cumbo, S., Torregrossa, S., \& Migliore, D. (2019). Treatment Effects of Vortioxetine on Cognitive Functions in Mild Alzheimer's Disease Patients with Depressive Symptoms: A 12 Month, Open-Label, Observational Study. The Journal of Prevention of Alzheimer's Disease, 6(3), 192-197. https://doi.org/10.14283/jpad.2019.24

de Bartolomeis, A., Fagiolini, A., \& Maina, G. (2016). Vortioxetina nel trattamento della depressione maggiore. Rivista Di Psichiatria, 51(6), 215-230. https://doi.org/10.1708/2596.26720

De Carlo, V., Calati, R., \& Serretti, A. (2016, June 30). Socio-demographic and clinical predictors of non-response/non-remission in treatment resistant depressed patients: A systematic review. Psychiatry Research. Elsevier Ireland Ltd.

Dell'Osso, B., Cremaschi, L., Arici, C., Altamura, A. C., Hooshmand, F., Do, D., ... Ketter, T. A. (2020). Differential core pharmacotherapy in bipolar I versus bipolar II disorder and European versus American patients not in a syndromal episode. International Clinical Psychopharmacology, 35(1), 8-18. https://doi.org/10.1097/YIC.0000000000000282

EMA (European Medicines Agency). (n.d.). EPAR Brintellix - Product Information. Annex I. Summary of Product Characteristics. Retrieved from http://www.ema.europa.eu/docs/en_GB/document_library/EPAR_Product_Information/human/002717/WC500159449.pdf

FDA. (2013). BrintellixTM (vortioxetine) tablets for oral use. Full Prescribing Information. Retrieved from http://www.accessdata.fda.gov/drugsatfda_docs/label/2013/204447s000lbl.pdf

Galimberti, C., Bosi, M. F., Caricasole, V., Zanello, R., Dell'Osso, B., \& Viganò, C. A. (2019). Using network analysis to explore cognitive domains in patients with unipolar versus bipolar depression: A prospective naturalistic study. CNS Spectrums. https://doi.org/10.1017/S1092852919000968

Grunze, H., Vieta, E., Goodwin, G. M., Bowden, C., Licht, R. W., Möller, H.-J., ... WFSBP Task Force on Treatment Guidelines for Bipolar Disorders. (2013). The World Federation of Societies of Biological Psychiatry (WFSBP) guidelines for the biological treatment of bipolar disorders: update 2012 on the long-term treatment of bipolar disorder. The World Journal of Biological Psychiatry: The Official Journal of the World Federation of Societies of Biological Psychiatry, 14(3), 154-219. https://doi.org/10.3109/15622975.2013.770551

Guy W. (1976). Dosage Record and Treatment Emergent Symptoms scale (DOTES). ECDEU Assessment Manual for Psychopharmacology - Revised. DHEW Publication No. ADM 76-338. NIMH Psychopharmacology Research Branch, Division of Extramural Research Programs, Alcohol, Drug Abuse,.

HAMILTON, M. (1959). THE ASSESSMENT OF ANXIETY STATES BY RATING. British Journal of Medical Psychology, 32(1), 50-55. https://doi.org/10.1111/j.20448341.1959.tb00467.x

HAMILTON, M. (1967). Development of a Rating Scale for Primary Depressive Illness. British Journal of Social and Clinical Psychology, 6(4), 278-296. https://doi.org/10.1111/j.2044-8260.1967.tb00530.x 
Henigsberg, N., Mahableshwarkar, A. R., Jacobsen, P., Chen, Y., \& Thase, M. E. (2012). A randomized, double-blind, placebo-controlled 8-week trial of the efficacy and tolerability of multiple doses of Lu AA21004 in adults with major depressive disorder. The Journal of Clinical Psychiatry, 73(7), 953-959. https://doi.org/10.4088/JCP.11m07470

Hughes, S., Lacasse, J., Fuller, R. R., \& Spaulding-Givens, J. (2017). Adverse effects and treatment satisfaction among online users of four antidepressants. Psychiatry Research, 255, 78-86. https://doi.org/10.1016/j.psychres.2017.05.021

Jacobsen, P. L., Harper, L., Chrones, L., Chan, S., \& Mahableshwarkar, A. R. (2015). Safety and tolerability of vortioxetine (15 and $20 \mathrm{mg}$ ) in patients with major depressive disorder: results of an open-label, flexible-dose, 52-week extension study. International Clinical Psychopharmacology, 30(5), 255-264.

https://doi.org/10.1097/YIC.0000000000000081

Jacobsen, P. L., Mahableshwarkar, A. R., Chen, Y., Chrones, L., \& Clayton, A. H. (2015). Effect of Vortioxetine vs. Escitalopram on Sexual Functioning in Adults with WellTreated Major Depressive Disorder Experiencing SSRI-Induced Sexual Dysfunction. The Journal of Sexual Medicine, 12(10), 2036-2048. https://doi.org/10.1111/jsm.12980

Jacobsen, P. L., Mahableshwarkar, A. R., Serenko, M., Chan, S., \& Trivedi, M. H. (2015). A randomized, double-blind, placebo-controlled study of the efficacy and safety of vortioxetine $10 \mathrm{mg}$ and $20 \mathrm{mg}$ in adults with major depressive disorder. The Journal of Clinical Psychiatry, 76(5), 575-582. https://doi.org/10.4088/JCP.14m09335

Jain, R., Mahableshwarkar, A. R., Jacobsen, P. L., Chen, Y., \& Thase, M. E. (2013). A randomized, double-blind, placebo-controlled 6-wk trial of the efficacy and tolerability of $5 \mathrm{mg}$ vortioxetine in adults with major depressive disorder. The International Journal of Neuropsychopharmacology, 16(2), 313-321. https://doi.org/10.1017/S1461145712000727

Katona, C., Hansen, T., \& Olsen, C. K. (2012). A randomized, double-blind, placebocontrolled, duloxetine-referenced, fixed-dose study comparing the efficacy and safety of Lu AA21004 in elderly patients with major depressive disorder. International Clinical Psychopharmacology, 27(4), 215-223. https://doi.org/10.1097/YIC.0b013e3283542457

Lochner, C., Fineberg, N. A., Zohar, J., Van Ameringen, M., Juven-Wetzler, A., Altamura, A. C., ... Stein, D. J. (2014). Comorbidity in obsessive-compulsive disorder (OCD): A report from the International College of Obsessive-Compulsive Spectrum Disorders (ICOCS). Comprehensive Psychiatry, 55(7), 1513-1519. https://doi.org/10.1016/j.comppsych.2014.05.020

Mahableshwarkar, A. R., Jacobsen, P. L., \& Chen, Y. (2013). A randomized, double-blind trial of $2.5 \mathrm{mg}$ and $5 \mathrm{mg}$ vortioxetine (Lu AA21004) versus placebo for 8 weeks in adults with major depressive disorder. Current Medical Research and Opinion, 29(3), 217226. https://doi.org/10.1185/03007995.2012.761600

Mclntyre, R. S. (2017). The role of new antidepressants in clinical practice in Canada: a brief review of vortioxetine, levomilnacipran ER, and vilazodone. Neuropsychiatric Disease and Treatment, 13, 2913-2919. https://doi.org/10.2147/NDT.S150589

Montgomery, S. A., \& Asberg, M. (1979). A new depression scale designed to be sensitive to change. British Journal of Psychiatry, 134(4), 382-389. https://doi.org/10.1192/bjp.134.4.382

Nomikos, G. G., Tomori, D., Zhong, W., Affinito, J., \& Palo, W. (2017). Efficacy, safety, and tolerability of vortioxetine for the treatment of major depressive disorder in patients aged 55 years or older. CNS Spectrums, 22(4), 348-362. https://doi.org/10.1017/S1092852916000626

Pae, C. U., Wang, S. M., Han, C., Lee, S. J., Patkar, A. A., Masand, P. S., \& Serretti, A. (2015). Vortioxetine: A meta-analysis of 12 short-term, randomized, placebo-controlled clinical trials for the treatment of major depressive disorder. Journal of Psychiatry and Neuroscience, 40(3), 174-186. https://doi.org/10.1503/jpn.140120

Papakostas, G. I. (2014). Cognitive symptoms in patients with major depressive disorder and their implications for clinical practice. The Journal of Clinical Psychiatry, 75(1), 8-14. https://doi.org/10.4088/JCP.13r08710 
Papakostas, G. I., Nielsen, R. Z., Dragheim, M., \& Tonnoir, B. (2018). Efficacy and tolerability of vortioxetine versus agomelatine, categorized by previous treatment, in patients with major depressive disorder switched after an inadequate response. Journal of Psychiatric Research, 101, 72-79. https://doi.org/10.1016/j.jpsychires.2018.02.017

Pehrson, A. L., Leiser, S. C., Gulinello, M., Dale, E., Li, Y., Waller, J. A., \& Sanchez, C. (2015). Treatment of cognitive dysfunction in major depressive disorder--a review of the preclinical evidence for efficacy of selective serotonin reuptake inhibitors, serotoninnorepinephrine reuptake inhibitors and the multimodal-acting antidepressant vortioxetine. European Journal of Pharmacology, 753, 19-31. https://doi.org/10.1016/j.ejphar.2014.07.044

Rizvi, S. J., \& Kennedy, S. H. (2011). The keys to improving depression outcomes. European Neuropsychopharmacology: The Journal of the European College of Neuropsychopharmacology, 21 Suppl 4, S694-702. https://doi.org/10.1016/j.euroneuro.2011.07.002

Rush, A. J., Trivedi, M. H., Wisniewski, S. R., Nierenberg, A. A., Stewart, J. W., Warden, D., ... Fava, M. (2006). Acute and longer-term outcomes in depressed outpatients requiring one or several treatment steps: A STAR ${ }^{\star} \mathrm{D}$ report. American Journal of Psychiatry, 163(11), 1905-1917. https://doi.org/10.1176/ajp.2006.163.11.1905

Salagre, E., Grande, I., Solé, B., Sanchez-Moreno, J., \& Vieta, E. (n.d.). Vortioxetine: A new alternative for the treatment of major depressive disorder. Revista de Psiquiatria $y$ Salud Mental, 11(1), 48-59. https://doi.org/10.1016/j.rpsm.2017.06.006

Serretti, A., \& Chiesa, A. (2009, June). Treatment-emergent sexual dysfunction related to antidepressants: A meta-analysis. Journal of Clinical Psychopharmacology. https://doi.org/10.1097/JCP.0b013e3181a5233f

Thase ME, Mahableshwarkar AR, Dragheim M, Loft H, V. E. (2016). A meta-analysis of randomized, placebo-controlled trials of vortioxetine for the treatment of major depressive disorder in adults. Eur Neuropsychopharmacol., 26(6), 979-993.

W., G. (1976). ECDEU Assessment Manual for Psychopharmacology, revised (DHEW Publ No ADM 76-338) National Institute of Mental Health; Rockville, MD: 1976. Clinical Global Impressions.

Young, R. C., Biggs, J. T., Ziegler, V. E., \& Meyer, D. A. (1978). A rating scale for mania: Reliability, validity and sensitivity. British Journal of Psychiatry, 133(11), 429-435. https://doi.org/10.1192/bjp.133.5.429

Zheng, Y., Severino, F., Hui, L., Wu, H., Wang, J., \& Zhang, T. (2019). Co-Morbidity of DSMIV Personality Disorder in Major Depressive Disorder Among Psychiatric Outpatients in China: A Further Analysis of an Epidemiologic Survey in a Clinical Population. Frontiers in Psychiatry, 10. https://doi.org/10.3389/fpsyt.2019.00833 